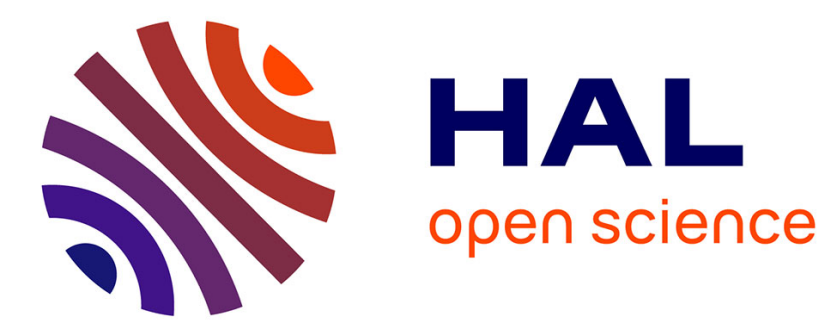

\title{
Review of CdTe medical applications
}

\author{
G. Entine, D.A. Garcia, D.E. Tow
}

\section{To cite this version:}

G. Entine, D.A. Garcia, D.E. Tow. Review of CdTe medical applications. Revue de Physique Appliquée, 1977, 12 (2), pp.355-359. 10.1051/rphysap:01977001202035500 . jpa-00244173

\section{HAL Id: jpa-00244173 https://hal.science/jpa-00244173}

Submitted on 1 Jan 1977

HAL is a multi-disciplinary open access archive for the deposit and dissemination of scientific research documents, whether they are published or not. The documents may come from teaching and research institutions in France or abroad, or from public or private research centers.
L'archive ouverte pluridisciplinaire HAL, est destinée au dépôt et à la diffusion de documents scientifiques de niveau recherche, publiés ou non, émanant des établissements d'enseignement et de recherche français ou étrangers, des laboratoires publics ou privés. 


\title{
REVIEW OF CdTe MEDICAL APPLICATIONS
}

\author{
G. ENTINE \\ Radiation Monitoring Devices, Inc. 44 Hunt St., Watertown, Massachusetts 02172, U. S. A. \\ D. A. GARCIA and D. E. TOW \\ Veterans Administration Hospital 1400 VFW Parkway, West Roxbury, Massachusetts 02132, U. S. A.
}

\begin{abstract}
Résumé. - L'emploi de détecteurs nucléaires au tellurure de cadmium commence à se développer dans plusieurs domaines de la médecine nucléaire. Ce type de compteur, dont l'usage était initialement limité à l'étude pathologique des dentures sur des modèles de chiens, commence à être mis en œuvre en clinique pour le diagnostic des tromboses des veines de la jambe et pour détecter des infections dentaires sur des patients devant subir une chirurgie orthopédique ou recevoir des prothèses cardiovasculaires. Des détecteurs similaires sont employés sur des animaux pour des travaux de recherches portant sur l'infarctus du myocarde ou sur la mise en place de dents synthétiques. Par ailleurs, les détecteurs CdTe ont été utilisés pour le diagnostic d'œdèmes pulmonaires par des mesures en transmission ou encore pour déterminer les changements de concentration des minéraux au cours de vols dans l'espace.

Des études sont également en cours en vue de l'application de ces dispositifs en imagerie nucléaire par spectroscopie $\gamma$ en une ou deux dimensions. Toutefois, des considérations économiques ralentissent ces recherches, bien que la technologie de base soit, en principe du moins, bien acquise.

Mentionnons pour finir que des travaux sont également en cours afin de développer des photoconducteurs $\mathrm{X}$ à base de CdTe pour les tomo-densitomètres; toutefois, des progrès importants sont nécessaires dans la qualité des détecteurs pour qu'ils puissent réellement s'imposer.
\end{abstract}

\begin{abstract}
CdTe sensors are now being used in several areas of nuclear medicine. CdTe probe technics, originally developed to study dental pathology in dog models, are being used clinically to diagnose venous thrombosis of the legs and to detect occult dental infections in patients scheduled for prosthetic cardiovascular and orthopedic surgery. Similar instrumentation is in use in animal research of myocardial infarction and synthetic tooth substitutes. Transmission technics have also been developed to diagnose pulmonary edema and to measure bone mineral changes in space flight.

Investigations are also underway in the use of linear or two dimensional arrays of CdTe gamma sensors for medical imaging. Economic considerations have slowed this work, but the technology appears to be available.

Development of photoconductive CdTe X-ray detectors for C. T. scanners has also begun. Rapid detector improvement will be needed for success in this field, but the potential usefulness is very great.

Together, the present application results are encouraging and wide use of CdTe detectors should occur within only a few years.
\end{abstract}

1. Introduction. - The rapid expansion of nuclear medicine stems from the unique type of information it can provide. By carefully designing a radiopharmaceutical to be preferentially taken up by one organ in a metabolically meaningful way, very specific information can be obtained about the condition of an organ long before structural changes or defects can be seen on radiographs. The large variety of radiopharmaceuticals on the market today reflects the numerous types of organ and tissue functions which are tested at the present time. The measurements range from total body imaging to dynamic function tests of small organs, and the demands placed on the current $\mathrm{NaI}$ detection devices are not adequately filled by the available instrumentation. The main purpose of this review is to consider the ways in which cadmium telluride can help satisfy some of the needs of this rapidly growing medical discipline.

2. Eye and needle probes. - One of these needs, which led to the first medical application, was miniaturization. The observation that eye tumors including melanoma would concentrate the beta-emitter ${ }^{32} \mathrm{P}$ led to the development of needle-like detectors containing the semiconductor silicon. The technic is used guardedly, however, due to the high radiation burden to the patient as well as to the counting errors owing to self-absorption of the beta-ray. In the 1960's the use of eye drops containing the gamma-emitter selenium-75 was proposed to supplant the hazardous agent ${ }^{32} \mathrm{P}$. As a result, Martini and colleagues developed a CdTe probe and demonstrated its superiority to a silicon 
detector in the eyes of rats [1]. As predicted, the CdTe probe was 29 times more sensitive to the gamma rays than the silicon probe. Unfortunately, the diagnostic value of ${ }^{75} \mathrm{Se}$ did not match that of ${ }^{32} \mathrm{P}$ and consequently no clinical applications have been reported to date. Needle-like variations of the CdTe eye probe design were constructed at this time for insertion into the body $[2,3]$. The intended usages were for cerebral blood flow measurements, as catheters in the detection of venous thrombosis and for localization of malignancies by direct contact with the suspected tissues. However, no reports of their subsequent clinical use are known to us at the present time.

3. Dental applications. - Our own work had its start as an attempt to solve a problem of spatial resolution $[4,5]$. The problem arose during a series of ongoing dog studies of dental infection preliminary to a human application, which will be described later. The two diagnostic goals of these studies were to detect pathology with gamma-emitting bone agents before it was radiographically apparent, and to localize small infectious lesions with precision. The animal test system consisted of two infected dog molars separated by a normal one. The crucial experiment was to identify the normal tooth in the presence of its acutely infected neighbours. The root tips of the infected teeth took up abnormally high amounts of Tc-99m-polyphosphate. Gamma camera and rectilinear scanner images produced diffuse hot spots which made it appear that all 3 teeth were diseased. Thus, these instruments were sensitive enough to detect pathology, but not to localize it.

The device we used to solve this problem was a small collimated probe held by hand in contact with the gingiva overlying the tooth roots. The instrumentation which is typical of that for many of the applications to be discussed, was as follows :

The detector was a $1 \mathrm{~cm}$ diameter by $2 \mathrm{~mm}$ thick cholorine-doped crystal with $7 \mathrm{~mm}$ diameter electrolessly deposited platinum contacts. A Tc-99m pulse height spectrum measured with the detector operated at 60 volts is shown in figure 1 . The collimator was a

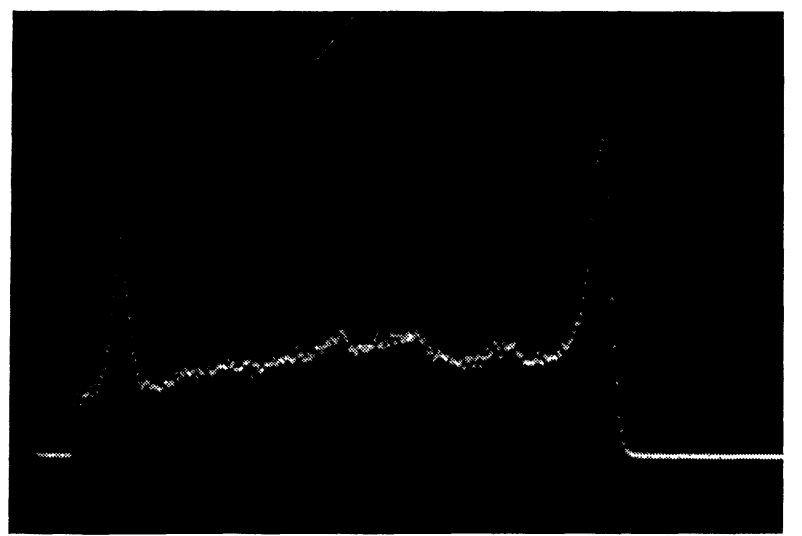

Fig. 1. - Pulse-height spectrum of Tc-99 $\mathrm{m}$ as measured with a collimated CdTe detector. Peaks at $20 \mathrm{keV}$ and $140 \mathrm{keV}$ have FWHM of $4.5 \mathrm{keV}$ and $6.6 \mathrm{keV}$, respectively.
$4 \mathrm{~mm}$ diameter by $1 \mathrm{~cm}$ long lead aperture. The associated electronics included a commercial timer, scaler, discriminator unit with the bias supply, preamplifier, and amplifier modified for use with the CdTe detector. The entire assembly is shown in figure 2 .

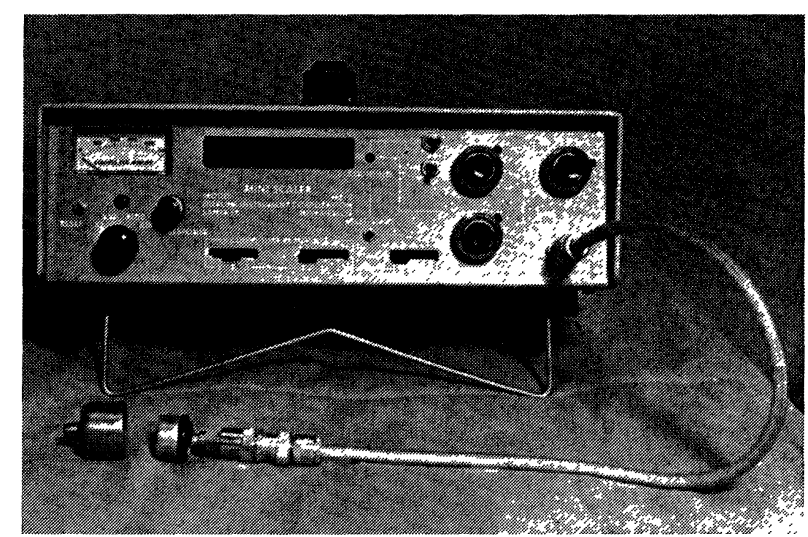

FIG. 2. - CdTe detector and associated scaler-ratemeter used to measure Tc-99 $\mathrm{m}$ activity in dog jaws. The detector shielded by a lead collimator, shown to the left, with a $4 \mathrm{~mm}$ diameter aperture.

Periodic count rate measurements with the handheld $\mathrm{CdTe}$ probe showed significant increases in Tc- $99 \mathrm{~m}$ uptake in the infected teeth while normal uptake was measured in the interposed, uninfected tooth. The distance between the root tips of adjacent teeth ranged from 6-9 $\mathrm{mm}$. Thus, differentiation of contiguous infected and normal dog teeth could be made with the CdTe probe but not with either a gamma camera or a rectilinear scanner.

Related dental applications are in progress at Harvard School of Dental Medicine, Boston, Massachusetts, U. S. A. Dr. Michael Kaplan and associates [6] are investigating bone changes in periodontal disease, the major cause of tooth loss after age 35. Bone imaging studies in a dog model of the disease have shown that certain areas of the jaws are affected earlier and more severely than others. The CdTe probe has provided them with more sensitive quantitative data than that obtained with conventional imaging devices.

Dr. Paul Schnitman and colleagues $\left({ }^{1}\right)$ of the same institution are evaluating various synthetic materials for implantation in the jaw as substitutes for missing teeth. Preliminary findings from experiments with baboons suggest that the use of bone agents and a CdTe probe may be useful in monitoring the healing and retention of implants within the jaws, and thereby in predicting the long-term success or failure of these tooth substitutes.

In both studies, the CdTe probe provided a degree of spatial resolution which was lacking in conventional $\mathrm{NaI}$ imaging instruments. Furthermore, the size and portability of the CdTe system have made possible the

(1) Schnitman, P., Zimmerman, R., Jeffcoat M., Private Communication. 
accumulation of data in animal facilities lacking $\mathrm{NaI}$ imaging devices, thereby obviating the logistical inconveniences of transporting animals to other locations. In the past, spontaneous movements of anesthetized primates during $30 \mathrm{~min}$ imaging procedures had necessitated repeated gamma camera measurements with all the associated risks of deep and prolonged anesthesia. The current method used to accumulate data is safer and more efficient through the use of multiple 1 min count rate measurements of selected sites on the jaws with the CdTe probe.

4. Cardiovascular uses. - This same compactness of design and portability of the CdTe system was the basis for the second application from our laboratory, which was the bedside screening of patients suspected of venous thrombosis of the legs [7].

This condition is a frequent complication following major surgery, such as breast removal and hiatus herniorrhaphy, in almost $35 \%$ of the patients over 40 . It is also a frequent complication of childbirth. Early detection of thrombi allows the initiation of therapy to prevent the migration of clots to the lungs which would produce pulmonary embolism. The radiopharmaceutical in this case was I-125-labelled autologous fibrinogen. The label is incorporated in a forming thrombus, and a clot can be localized by the external detection of abnormal accumulations of radioactivity.

Further modifications of the electronics used for the Tc-99m dog tooth study were needed because of the lower energy of the I-125 gamma radiation (28 keV). The noise level was reduced to $9 \mathrm{keV}$ by using a low bias voltage of $30 \mathrm{~V}$ and a new preamplifier. Furthermore, cable noise was eliminated by placing the FET gain block of the preamplifier next to the detector rather than at the other end of the meter long cable leading to the main package. An I-125 spectrum measured with the CdTe detector is shown in figure 3 .

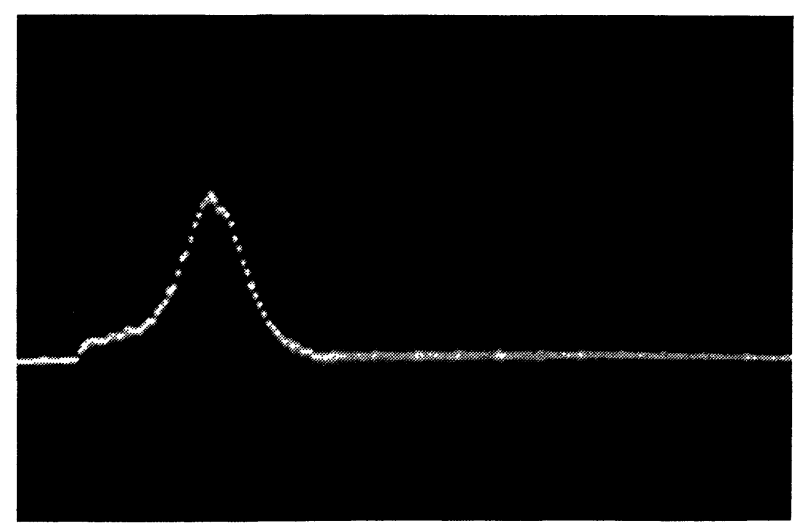

Fig. 3. - The spectrum of I-125 as measured by the CDTe probe

The preamplifier head, which measures $3 \times 2 \times 4 \mathrm{~cm}$, serves as a convenient handle for clinical use. The completed CdTe package, including a compact lead collimator, is shown in figure 4, where it is compared to a standard NaI probe (Model 235, Pitman Isotope Localization Monitor) designed for bedside use.

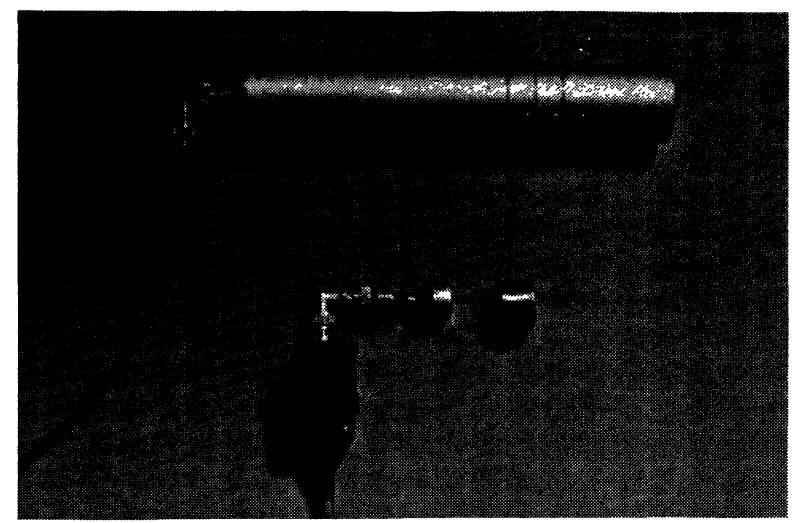

FIG. 4. - The NaI (above) and CdTe (below) probe systems used for detection of I-125-labelled blood clots. The FET gain block of a low noise pre-amplifier was placed close to the CdTe detector to reduce cable noise. A lead collimator is shown to the right of the CdTe detector.

The clot detecting capability of the CdTe probe was compared to that of the standard $\mathrm{NaI}$ probe in a series of patients by measuring I-125 activity at selected sites on the legs. The results showed that the CdTe probe was the equal of the $\mathrm{NaI}$ probe in diagnostic capability. The compactness of the CdTe instrument, approximately one tenth the size of the NaI sensor, facilitated accurate and reproducible placement of the probe. Figures 5 and 6 show the placement of the $\mathrm{NaI}$ and CdTe detectors, respectively, over a calf site. The smaller size of the CdTe probe was found to be of particular advantage in tests of bedridden patients of limited mobility.

Another cardiovascular application of CdTe probes is being conducted by Dr. Leonard Holman of the Peter Bent Brigham Hospital and Harvard Medical School, Boston, Massachusetts, U.S. A. $\left(^{2}\right)$.The purpose of the study is to measure the efficiency of therapeutic interventions in reducing the size of myo. cardial infarctions.

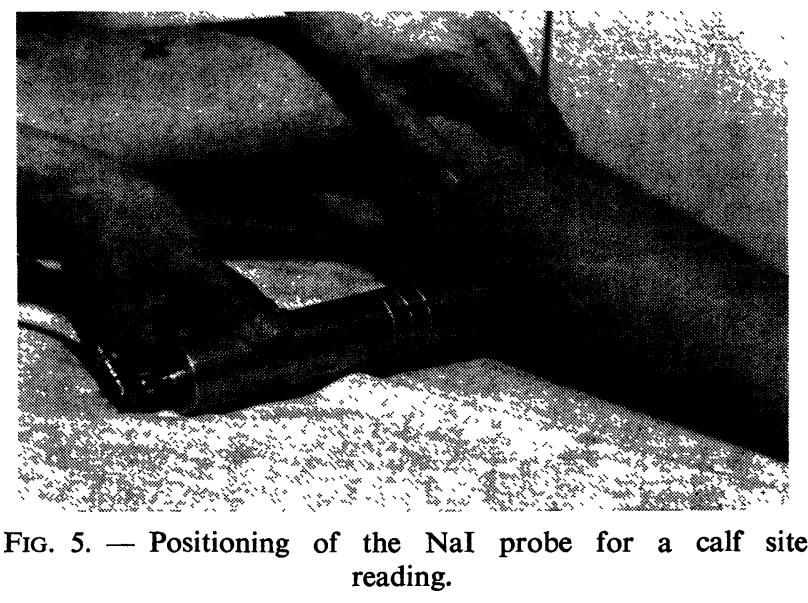

(2) Holman, L., Private Communication. 


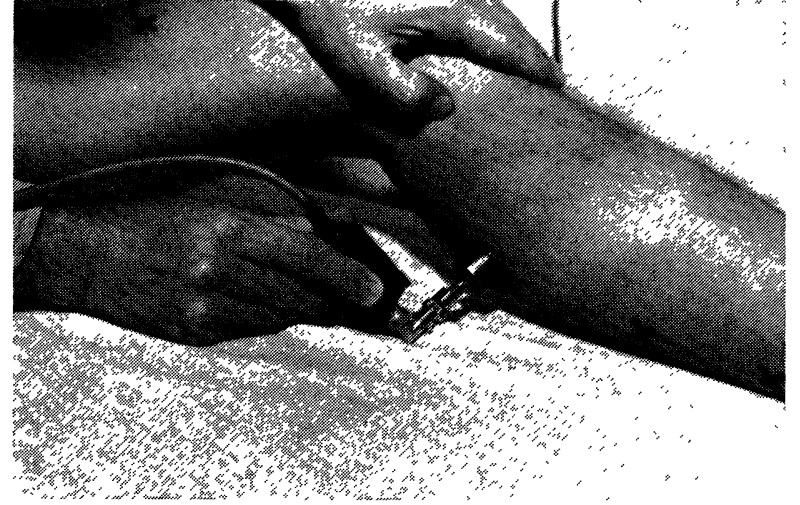

FIG. 6. - Positioning of the CdTe probe for a calf site reading.

Infarcts are produced in test animals by mechanical occlusion of the coronary artery for 8 to 12 hours. Tc-99m pyrophosphate is administered intravenously and accumulates in the damaged tissue. An open chest preparation is used and point by point counting with a collimated CdTe probe allows accurate determination of infarct size. Therapeutic intervention is then performed and periodic measurements are taken to assess the effect of the treatment.

The test animals are dogs and previous work using $\mathrm{NaI}$ gamma cameras encountered difficulty in making accurate measurements because of the high radioactive background being emitted by the Tc-99m absorbed in the breast bone. By using the small CdTe probe which can be placed very near to the heart, the background counts can be blocked by the collimator and precise readings can be obtained.

5. Transmission technics. - One of the most advanced medical instruments using CdTe sensors is the lung densitometer developed by Dr. Leon Kaufman's [8] group at the University of California, San Francisco Medical Center. The details of this work will be presented in another paper in this session, but it is worthwhile to mention just a few of the highlights. The lung densitometer measures both a direct transmitted gamma beam and a scattered beam with a pair of CdTe sensors. With this approach, very accurate measurements of the density of the lung can be obtained for the purpose of diagnosing pulmonary edema. Because of the low intensity of the scattered beam, it is important that background counts be reduced to the lowest possible levels. The compactness of the CdTe detectors makes shielding from background radiation much more convenient. The instrument is quite sensitive and is now being tested clinically.

Another project which will also be discussed in a later paper by Dr. John Vogel, involves the use of $\mathrm{CdTe}$ to monitor bone mineral content during space flight. By using I-125 as the source, high sensitivity absorption measurements can be made with good linearity and counting rates. The compactness of this detector-preamplifier combination is of prime importance in the space field and should become the sensor of choice as the technology progresses.

6. Presurgical oral diagnosis. - As mentioned previously, the tooth abscess studies in dogs were preliminary to a patient study which we have just initiated. The purpose of this study is to improve the current oral diagnostic methods used in screening patients scheduled for prosthetic cardiovascular and orthopedic surgery.

With the improvement of surgical technics over the last five years, the number of patients undergoing reconstructive surgery such as heart valves and hip joints has increased dramatically.

Recent reports indicate that from 1 to $6 \%$ of these patients experience severe postoperative infections, sometimes with fatal results. It is now believed that a significant fraction of these problems arise from subacute dental infections which were present in the patient before the operation, but not detectable by standard means.

A preoperative diagnostic screening for these patients is now being tested in which a Tc-99m labelled phosphate agent is used to detect these infections. The agent is given intravenously, and standard NaI instruments are used to make images of the jaws.

Our preliminary findings are that bone imaging can detect infarctious dental lesions that are not apparent either radiographically or by other conventional technics. The camera images are sufficient to indicate the presence of infection but not to localize it to a specific tooth. Using the technic developed on the animal model, the CdTe probe precisely identifies the infected tooth.

7. Photon counting imaging systems. - Fixed imaging devices, such as the camera, use very large NaI crystals with multiple photomultipliers to provide the two dimensional information needed for the picture.

Semiconductor detector arrays have been considered for improved energy resolution, counting speed, and mechanical convenience. In particular, work has been done to make germanium cameras by putting a row of parallel line electrodes on top of the crystal and another but perpendicular electrode array on the bottom, similar to a multiwire ion chamber. The substitution of $\mathrm{CdTe}$ for germanium is under investigation at several laboratories. The CdTe should be much easier fto work with than the germanium and could become the basis of an imaging system small enough to be conveniently brought to a patient's bedside. The key technical questions are whether large enough areas of uniform CdTe can be assembled economically and whether a large enough percentage of the rays can be absorbed with detectors of reasonable thickness while maintaining the energy resolution.

Another imaging system, using a linear array of detectors is also being developed for bedside use. The 
use of the linear configuration reduces the uniformity requirements since the individual preamplifiers can be tuned to compensate for charge collection variations. In addition, if the elements are small enough in one direction (e. g. $2 \mathrm{~mm}$ wide), they can be used edge on to provide excellent stopping power. The main hurdle for this application is economic since the total system price must be kept relatively low.

8. C. T. Scanners. - The most dramatic instrument used today in radiology is, of course, the C. T. Scanner. With this instrument, very high resolution $\mathrm{X}$-ray images of transverse sections of the brain or body can be made.

The original scanner, developed by EMI in 1972, used a collimated X-ray source mechanically coupled to a $\mathrm{NaI}$ detector which was linearly scanned across the head of the patient. The source and detector were then rotated by one degree and the scan repeated. By doing 180 scans, each point within the head was measured from all angles in the plane. In a manner similar to how one could estimate the appearance of an apple orchard from above by simply looking at it from all sides, a computer uses the X-ray data to construct a picture of a plane of the head as seen from above.

Although the instrument was a major breakthrough in medicine, the full scan required twenty minutes which led to some technical problems and patient discomfort. In the last year, instruments have been developed using multiple detectors and extended X-ray sources which reduce the scan time to a few seconds.

While these instruments rely on up to $50 \mathrm{NaI}$ or Xenon sensors, future machines will use 200 or 600 detectors and there is much interest in using CdTe. Firstly, the mechanical aspects of the solid state detector have great appeal. A typical CdTe detector element would be $1 \mathrm{~cm}$ high by $2 \mathrm{~mm}$ wide and only $4 \mathrm{~mm}$ deep compared with the Xenon tube of several inches deep or the NaI detector with its photomultiplier. These mechanical advantages are quite important since the detectors may have to rotate completely around a one meter diameter circle in less than a second. In addition, the lower energy required to produce a charge pair in CdTe $(4.5 \mathrm{eV})$ compared to the two other sensors $(30 \mathrm{eV})$ leads to a theoretically high signal to noise ratio Finally, the solid state nature of the device not only simplifies the electronics but also provides excellent stability and almost infinite working life.

The difficulties which must be overcome before CdTe will be practical are both technical and economic. The photon flux rate is often well above $10^{7}$ per second so that it is necessary to run the detectors with very short clipping times and high fields. or in the photoconductive mode.

Little work has been done in the photoconductive mode and it remains to be seen what the ultimate time response and linearity of $\mathrm{CdTe}$ will be. Initial photoconductive results are encouraging, especially because the detectors show good reproducibility from one to the next. Sevesal time constants are found in the detectors which are primarily a function of device design. By properly matching the electrode fabrication technic to the modulation of the X-ray source, promising results have been achieved. Experiments are now underway to develop a detector suitable for all time domains.

From an economic point of view, it is necessary for the detector and an associated preamplifier to be relatively inexpensive. Recent improvements in the manufacturing technology of $\mathrm{CdTe}$ such as that reported earlier in the conference should make it possible to achieve in the very near future the cost goals required for this very large volume application.

9. Conclusions. - CdTe detectors are now readily available to satisfy certain requirements of the type of external probe instruments discussed above for use in the detection of venous thrombosis and dental infections. Minor advancements in the commercialization of the detectors would result in the widespread acceptance of CdTe instrumentation for this work.

$\mathrm{CdTe}$ photon counting imaging tystems such as the linear array scanner can now be achieved technically, but will require significant economic commitment to bring the detector cost low enough to make the projects feasible. Nevertheless, the basic cost projections make it likely that these systems will become reality over the next two or three years.

The application which could have the largest impact on the field is the C. T. Scanner. If the needed technical development to make fast photoconductive detectors can be completed within the next twelve months, CdTe could become the basis for many of the next generation of this system. The economic fallout from such an event would have a huge impact on all aspects of the CdTe detector field and should make possible the attainment of much of the theoretical potential of the semiconductor.

Acknowledgements. - This work was supported in part by ERDA Contract E (11-1)-2541.

\section{References}

[1] Meyer, E., Martini, M., Sternberg, J., IEEE Trans. Nucl. Sci. 19 (1972) 237.

[2] Walford, G. V., Parker, R. P., IEEE Trans. Nucl. Sci. 20 (1973) 318

[3] WALFORD, G. V., MARTINI, M., 1972, Third International Conference on Medical Physics, Gothenburg, Sweden.

[4] Entine, G., Serreze, H. B., Garcia, D. A., IEEE Trans. Nucl. Sci. 21 (1974) 726.
[5] Garcia, D. A., Entine, G., Tow, D. E., J. Nucl. Medicine, $15(1974) 892$

[6] Kaplan, M. L., Garcia, D. A., David, M. A., Adelstein, S. J., Goldhaber, P., Calcified Tissue Research 19 (1976) 91.

[7] Garcia, D. A., Frisbie, J. H., Tow, D. E., Sasahara, A. A., ENTINe, G., IEEE Trans. Nucl. Sci. 23 (1976) 594.

[8] Kaufman, L. et al., IEEE Trans. Nucl. Sci. 23 (1976) 498, also Private Communication. 